\title{
Community projects: an experimental analysis of a fair implementation process
}

Article

Accepted Version

Cicognani, S., D'Ambrosio, A., Güth, W., Pfuderer, S. and Ploner, M. (2015) Community projects: an experimental analysis of a fair implementation process. Social Choice and Welfare, 44 (1). pp. 109-132. ISSN 1432-217X doi: https://doi.org/10.1007/s00355-014-0822-y Available at https://centaur.reading.ac.uk/41036/

It is advisable to refer to the publisher's version if you intend to cite from the work. See Guidance on citing.

Published version at: http://dx.doi.org/10.1007/s00355-014-0822-y

To link to this article DOI: http://dx.doi.org/10.1007/s00355-014-0822-y

Publisher: Springer

All outputs in CentAUR are protected by Intellectual Property Rights law, including copyright law. Copyright and IPR is retained by the creators or other copyright holders. Terms and conditions for use of this material are defined in the End User Agreement.

\section{www.reading.ac.uk/centaur}

\section{CentAUR}

Central Archive at the University of Reading 
Reading's research outputs online 


\section{Community Projects}

\section{An Experimental Analysis of a Fair Implementation Process}

3 Simona Cicognani • Anna D'Ambrosio • Werner

4 Güth · Simone Pfuderer • Matteo Ploner

6 Received: date / Accepted: date

7 Abstract We define and experimentally test a public provision mechanism that meets three basic ethical requirements and allows community members to influence, via monetary bids, which of several projects is implemented. For each project, participants are assigned personal values, which can be positive or negative. We provide either public or only private information about personal values. This produces two distinct public provision games which are experimentally implemented and analysed for various projects. In spite of the complex experimental task, participants do not rely on bidding their own personal values as an obvious simple heuristic whose general acceptance would result in fair and efficient outcomes. Rather, they yield to strategic underbidding. Although underbidding is affected by projects' characteristics, the provision mechanism leads to the implementation of the most efficient project mostly.

Keywords Public Provision · Procedural Fairness · Experiment JEL classification: C91; C72; D63.

Ploner (corresponding author)

Cognitive and Experimental Economics Laboratory, University of Trento

Via Inama, 5

38122 Trento (Italy)

Tel.: +390461283139

Fax: +390461282222

E-mail: matteo.ploner[at]unitn.it

Cicognani, D'Ambrosio, and Pfuderer

School of Social Sciences, University of Trento (Italy)

Güth

Max Planck Institute of Economics, Jena (Germany) 
In the real world projects that may benefit one party but harm another party 24 are frequently observed. Such projects may give rise to the so-called "Not In My Backyard" (NIMBY) syndrome if they improve general welfare but generate costs for the individuals living close to the project who, as a consequence, oppose its implementation (e.g., Frey and Oberholzer-Gee, 1997). As an example, building a new railway may improve the general welfare of the community. However, while it may benefit some individuals, such as the traders in the community, at the same time, it may harm farmers whose land is needed to build it. Therefore, farmers might oppose and try to prevent the implementation of the railway.

Following the seminal work of Rapoport and Chammah (1965) on the Prisoner's Dilemma, the provision of public goods has been the object of a variety of experimental studies. Generally, participants in a public goods game are asked to contribute to a public good that generates positive externalities for the potential contributors, irrespectively of the actual amount contributed (Bergstrom et al., 1986). The public good is usually assumed to yield benefits to all participants and the size of benefits is usually found to positively affect the contributions to the public good (see, for a review, Ledyard, 1995). In an attempt to replicate field conditions, experimental studies have introduced extensions to this basic setting, investigating among other the effect of heterogeneous valuations of the good (e.g., Bagnoli and McKee, 1991; Rondeau et al., 1999) and of negative externalities (e.g., Andreoni, 1995; Sonnemans et al., 1998). However, the empirically relevant case of public projects yielding benefits to some and harming other participants has only recently been addressed in the experimental literature (e.g., Güth et al., 2011).

For projects that benefit some and harm others, it is essential that the rules governing the choice and the allocation of the overall benefit from the project are fair and that equal weight is attributed to each participant. Güth and Kliemt (2013) axiomatically derive a procedurally fair institution. Individuals involved in decision-making within this institution bid on the provision of a set of projects, 
whose provision points are publicly known. Through their bids, participants state the maximum contribution they are willing to make to the project given the information available. ${ }^{1}$ The bids can be negative and, if low enough, veto the implementation of the project.

Assuming the common measuring rod of money for whatever the concerns are, fairness is guaranteed with respect to the publicly observable bids. The fairness condition implies that participants obtain the same net benefit with respect to their bids. The "status quo" is maintained when the bids do not justify provision, whereas when bids render implementation justifiable, the set of projects with the largest surplus, i.e. the largest difference between the sum of the bids and the costs, is selected.

The procedurally fair institution of Güth and Kliemt (2013) constitutes the game form implemented experimentally by Güth et al. (2011) and also in this paper (see Section 2.1 for a detailed description). Güth et al. (2011) compare bids and provision rates for a public good project that harms some and benefits others and for a less efficient traditional public good project. The authors label the latter "mixed feelings" project. Güth et al. (2011) experimentally study bids and provision rates in the simple case where two players, who have common knowledge about personal values, bid for two projects, with one player always having higher values than the other. Their results show that, while participants generally succeed in selecting the most efficient project, the provision frequency of the mixed-feelings project reduces when in competition with the traditional public good.

Compared to Güth et al. (2011), we investigate mixed feelings in a much richer experimental setting, with groups of three players that bid for seven projects over five different sets of personal values and costs (we call these sets "prospects"). Moreover, unlike Güth et al. (2011), we study behaviour in two alternative information conditions: a public information setting and a private information setting. In both, participants know the project costs, but in the private information setting

\footnotetext{
1 Kunreuther and Portney (1991) in the context of the NIMBY literature propose a similar approach to guide decision making for the siting of noxious facilities.
} 
they are only aware of their own personal values, whereas in the public information setting they also know others' personal values and are, thus, able to calculate the social benefits of each project. This innovation in the experimental design allows us to verify the applicability of the institution in absence of the common knowledge requirements of game theory and to control for the impact of social preferences. Furthermore, the complex experimental setting adopted brings us closer to field conditions and allows us to investigate the role of costs, heterogeneity in values, negative personal values, and social benefits on bidding and provision.

Our results show that there is a general tendency to post a bid lower than one's own personal value (i.e., underbidding), and, in turn, this affects the creation of surplus. Negative personal values promote underbidding and endanger the implementation of efficient projects. Also heterogeneous valuations have a negative impact on bids, echoing an established finding in the experimental literature on public goods according to which homogeneity increases contributions (Ledyard, 1995). Furthermore, variance in personal values may explain failures to provide the most efficient project because it inhibits coordinating on bids that ensure implementation. We find that when all personal values are the same, the most efficient project has the highest implementation rate across all prospects. With reference to the two information conditions, our results show that common knowledge of others' evaluations does not substantially affect bidding behaviour and project implementation. When deciding how much to bid, participants seem to focus on their own personal values. Behaviour of this kind is compatible with the axiomatic derivation of game forms rather than proper games formalised in Güth and Kliemt (2013) that does not require common knowledge assumptions.

The paper is organised as follows: Section 2.1 presents the theoretical basis (game format) underlying the experiment; Section 2.2 outlines the experimental design and the behavioural predictions; Section 2.3 describes the procedure followed to conduct the experiment; Section 3 presents the results of the experiment; Section 4 discusses and concludes. 


\section{Method}

\subsection{The Game Format}

To derive our mechanism, we postulate three requirements, two of which are rather obvious. Each participant $i \in N=\{1, \ldots, n\}$ with $n \geq 2$ submits a bid $b_{i}(S)$ for each different combination (subset) $\mathrm{S}$ of a certain finite number of possible measures $\Omega$. Each subset is associated with known costs $(C(S))^{2}$

Requirement 1 Efficiency with respect to bids

If $\forall \emptyset=S \subset \Omega$, $\sum_{i=1}^{n} b_{i}(S)<C(S)$, then $S^{*}=\emptyset$ Otherwise, $S^{*} \neq \emptyset$ and $\forall S \subset \Omega$ $\sum_{i=1}^{n} b_{i}\left(S^{*}\right)-C\left(S^{*}\right) \geq \sum_{i=1}^{n} b_{i}(S)-C(S)$.

This ensures that for a subset which is implemented the sum of all bids must be equal or higher than its costs. Among all subsets, only a subset $S^{*}$ with the highest surplus is selected. In the experiment, the surplus $(S P)$ of each project is defined as the difference between the sum of the bids for that project by the $n$ participants in a group $\left(\sum_{i=1}^{n} b_{i}\right)$ and the cost $C$ of that project $\left(S P=\sum_{i=1}^{n} b_{i}-C\right)$. Requirement 1 states that the project with the highest surplus, when this is non-negative, is implemented. If the highest surplus is negative, no project is implemented.

\section{Requirement 2 Cost balancing}

$\sum_{i=1}^{n} p_{i}\left(S^{*}\right)=C\left(S^{*}\right)$

If $S^{*} \neq \emptyset$, denote by $p_{i}\left(S^{*}\right)$ the payment required from each $i \in N$. Requirement 2 ensures that the sum of all payments covers the costs. ${ }^{3}$

Requirement 3 Equal payoff with respect to bids

$b_{i}\left(S^{*}\right)-p_{i}\left(S^{*}\right)=b_{j}\left(S^{*}\right)-p_{j}\left(S^{*}\right)=\triangle$ for all $i, j=1, \ldots, n$

2 Costs could be negative, for example, when implementation is generating revenues rather than costs. However, this possibility is neglected here.

3 One could allow for taxing or subsidising public provision; for example in the form of $\sum_{i=1}^{n} p_{i}\left(S^{*}\right)+c=C\left(S^{*}\right)$ for some given $c \in \mathbb{R}$. However, this is neglected here. 
The main requirement, allowing to characterise many institutions in practical use for centuries (Güth, 2011), postulates equal treatment of all parties according to what can be monitored objectively, i.e. the bids. The difference $\triangle$ between the bid and the actual payment, i.e., the players' payoff with respect to bids, must be the same for all participants. ${ }^{4}$ From these requirements it follows for the selected subset $S^{*}$, if it is not empty, that the payment is the bid minus an equal share of the highest non-negative surplus. ${ }^{5}$ Thus, the payments are computed as follows: $p_{i}\left(S^{*}\right)=b_{i}\left(S^{*}\right)-\left(\sum_{j=1}^{n} b_{i}\left(S^{*}\right)-C\left(S^{*}\right)\right) / n$ for all $i \in N .^{6}$

In order to implement this mechanism in the experimental setting, we need to assign exogenously given personal values $v_{i}(S)$ to participants. Personal values measure the pleasure or displeasure for each participant in case the subset is implemented. To illustrate this point, take the example of a community that is made up of families living in a block of flats. A family living on the third floor will benefit more from an elevator than a family living on the ground floor. In our experiment this will be translated in a higher personal value for the family living on the third floor. ${ }^{7}$

The overall benefit to the community, social benefit $(S B(S))$, is captured by the difference between the sum of the personal values and the cost. The overall benefit to the individual is captured by her payoff, understood as net gains compared to the status quo denoted by $\emptyset$. The payoff $\pi_{i}$ for participant $i$ is the difference between her personal value and her payment for the selected subset: $\pi_{i}=v_{i}\left(S^{*}\right)-p_{i}\left(S^{*}\right)$,

\footnotetext{
4 Note that this implies envy-free net-trades according to bids (Güth, 1986) and truly equal payoffs in case of each bidder $i$ bidding for each subset $S$ his exogeneously given personal value. Furthermore, it is an essential feature of our approach to allow for negative bids. Any proportionality principle would require an arbitrary lower bound for bids and this questions the universal application of the mechanism.

5 This proves an important voluntariness property or veto principle since by bidding sufficiently low one can veto all sets $S \neq \emptyset$.

6 Requirement 3 implies $b_{i}\left(S^{*}\right)-p_{i}\left(S^{*}\right)=\triangle \in \mathbb{R}$ or $b_{i}\left(S^{*}\right)=p_{i}\left(S^{*}\right)+\triangle$ for all $i \in N$. Due to $\sum_{i=1}^{n} b_{i}\left(S^{*}\right)=\sum_{i=1}^{n} p_{i}\left(S^{*}\right)+n \triangle$ and $\sum_{i=1}^{n} p_{i}\left(S^{*}\right)=C\left(S^{*}\right)$, we obtain $\triangle=\left(\sum_{j=1}^{n} b_{i}\left(S^{*}\right)-\right.$ $\left.C\left(S^{*}\right)\right) / n \geq 0$ and thus $p_{i}\left(S^{*}\right)=b_{i}\left(S^{*}\right)-\left(\sum_{j=1}^{n} b_{i}\left(S^{*}\right)-C\left(S^{*}\right)\right) / n$ for all $i \in N$.

7 Personal values should not be interpreted as endowments, but as benefits/ disbenefits from implementing a certain project, irrespective of the reasons that led to this valuation.
} 
with $v_{i}(\emptyset)-p_{i}(\emptyset)=0-0=0$. Given the definition of payments $p_{i}\left(S^{*}\right)$, we get: $\pi_{i}=v_{i}-b_{i}+\frac{S P}{n}$ with $S P=\sum_{i=1}^{n} b_{i}\left(S^{*}\right)-C\left(S^{*}\right)$ for $i=1, \ldots, n$. Although we will introduce personal values for all possible alternatives, the mechanism proposed for voluntary public provision does not need such exogenously given evaluations to collectively provide community projects. In this sense, our mechanism resembles democratic voting rules which only define the set of voters and how many votes are required for certain outcomes. In game-theoretic terminology, this means that the mechanism analysed here only defines a game form but no proper (Bayesian) game.

For exogenously given personal values, the mechanism would yield a welldefined game — and not just a game form — when these values are assumed to be commonly known. We will implement this well-defined game experimentally in one of our two treatments, the public information treatment, where all personal values and costs are known to all participants. If the personal values are only privately known, as in our private information treatment, a well-defined (Bayesian) game would have to rely on commonly known (consistent or inconsistent) beliefs concerning them. Our mechanism like democratic voting rules and, more generally, legally codified mechanisms does not require well-defined games (see Güth, 2011, for a discussion of public procurement auctions in this sense). It is an important advantage of our approach that the mechanism is applicable, irrespectively of whether the requirements of common knowledge are granted. ${ }^{8}$

Under standard assumptions, every bidding strategy $b_{i}(\cdot)$ specifying bids $b_{i}(S)$ higher than the personal value of bidder $i$ for some subset $S$ is weakly dominated, i.e. the bidding mechanism is overbidding proof. ${ }^{9}$ However, the mechanism is not incentive-compatible since bidders can gain by underbidding their personal values. In case of commonly known personal values and at least one subset $S$ of $\Omega$ which is

8 The same applies to democratic election rules and, more generally, to legally codified mechanisms which must be applicable across the board, i.e. even to the usual "ill-defined cases".

9 Overbidding may result in a pocket-money loss in the experiment and in a disadvantageous final allocation for those overbidding relative to those not overbidding. This makes overbidding quite unlikely also for individuals endowed with conventional social preference. 


\subsection{Experimental Design and Behavioural Predictions}

In our experiment we consider a community $N=\{1,2,3\}$ with three members and five different prospects. Each prospect contains seven subsets of measures. Hereafter, for simplicity, we refer to each subset of measures as a project. Each project is associated with costs $(\mathrm{C})$ and personal values $\left(v_{1}, v_{2}, v_{3}\right)$. Participants are randomly matched in groups of three. Two alternative experimental treatments are implemented in a between-subjects design. In one condition participants are informed only of their own personal values (Private information). In the alternative condition participants are informed also of the personal values of the other two group members and are aware that the others are informed too (Public information).

When introducing and justifying our mechanism it should be clear that we do not subscribe to the usual request for a game theoretic benchmark. Actually, for one treatment, namely the one with commonly known personal values, a multiplicity of equilibria exists that all implement the most efficient subset $S^{*}$ of $\Omega$ as characterised informally above. We could single out the one with equal payoffs

\footnotetext{
10 A project is efficient according to personal values when the sum of the personal values for some $S$ at least covers its cost $C(S)$.

11 This, of course, applies also to mechanisms which are dominance solvable. However, such mechanisms are more often than not impossible (see Güth, 2011).
} 
for all bidders (according to personal values rather than only according to bids) if one cares for a unique benchmark solution. This equilibrium requires that all bidders underbid their personal value for $S^{*}$ by the same amount. For the case of privately known personal values, a benchmark solution would require commonly known prior beliefs, which we intentionally did not try to induce experimentally to demonstrate the general applicability of our approach, irrespective of the empirically unrealistic assumption of common knowledge.

The institution we experimentally investigate is based on three requirements leading to a fair and efficient outcome with respect to bids. Fairness is defined with reference to bids (procedural fairness) and can lead to different payoffs, i.e., it does not necessarily lead to fair outcomes with respect to payoffs. However, if all participants bid their personal values, the payoffs are equal. Thus, general bidding of one's personal values would generate a "fair and efficient outcome" both with respect to bids and with respect to personal values. We focus here on procedural fairness as resulting from the equality of payoffs with respect to bids.

While procedural fairness is still quite unexplored in economic studies, a lot of attention has been paid in recent years to outcome-based fairness and to social preferences in general. Several sources of fairness have been identified in the literature, like inequity aversion (e.g., Fehr and Schmidt, 1999; Bolton and Ockenfels, 2000), altruism (e.g., Andreoni and Miller, 2002), and welfare-enhancing preferences (e.g., Charness and Rabin, 2002). In our framework, other regarding concerns are not exogenously given but a result of analysing a given social decision problem. Actually, one of the intuitions of procedural fairness is that procedural fairness may crowd out other regarding concerns. This can be seen from sports contests or markets which are usually procedurally fair and hardly ever offer evidence of other regarding concerns, at least when entitlement is granted. We do not provide here a direct test of outcome-based social preferences, but the two information treatments provide us with some control of their relevance in the setting under investigation. While in the private information condition considerations of 

this kind should not play a relevant role, in the public information treatment they could. ${ }^{12}$ Thus, differences in bids between the two conditions may potentially be ascribed to social preferences based on outcomes.

With reference to cognitive aspects of the decision process, the complexity of the mechanism seems to require a substantial amount of resources when choosing a specific course of actions. In particular, underbidding requires quite complex strategic considerations which participants might want to avoid. Bidding one's own personal values could therefore qualify as an obvious heuristic (see, more generally, on heuristics, Gigerenzer and Todd, 2000). Hence, this is a possible focal "fair" benchmark to start from. ${ }^{13}$ Indeed, one of the reasons to study rather complex prospects is to provide a basis for relying on heuristics rather than on strategic underbidding. However, bidding personal values is not in general a (Nash) equilibrium. $^{14}$

For example, if the costs of the project are 15 and the personal values of the three players are $12,-4$ and 25 , respectively, bidding personal values leads to a surplus of 18 and a payoff per person of 6 . However, in this situation, players have an incentive to underbid. If the participant with personal value of 12 lowers her bid from 12 to 0 , the project would still be implemented but she would earn more, namely $12+2=14$ instead of 6 . However, she can do even better by bidding -6 . In this case, she would get all the social benefit (18). ${ }^{15}$

This example clearly demonstrates that bidding personal values is weakly dominated and that one should expect strategic underbidding (bid shading), similarly to what happens in the provision point literature (Bagnoli and Lipman, 1989; Marks and Croson, 1998; Cadsby and Maynes, 1999) and experimental first-price auctions (Kagel, 1995). It has to be expected that many participants will under-

12 We thank an anonymous reviewer for pointing out this issue.

13 The same outcome would be achieved if all participants under- or overbid by the same amount; however, this seems rather unlikely, even when personal values are commonly known and quite unimaginable when not.

14 Exceptional cases are when personal values add up to the costs.

15 The same logic applies to participants with negative personal values that may try to increase their payoff by posting a negative bid smaller than their personal value, provided of course that the other bids cover the costs and compensate her negative bid. 
stand such underbidding incentives and even more so with more familiarity. Thus, even when first considering bidding personal values as an easy option they later might tend to underbid their personal value. While we expect that, behaviourally, participants will take their personal values as a reference for their bids, we also expect systematic underbidding, especially when personal values are only privately known. According to the anchoring heuristic (Tversky and Kahneman, 1974), participants may underbid by some amount (see also Güth et al., 2011), even though the extent of underbidding can hardly be predicted. In contrast, overbidding should be very unlikely as it is weakly dominated and can even lead to negative payoffs. Rondeau et al. (1999) in their review of the provision point literature find that contributions range from $40.2 \%$ to $85.0 \%$ of the induced values.

In our work, we focus on the effects of the information setting (private versus public) and of different prospects on bidding behaviour. We expect that knowing other participants' values will affect bidding behaviour because participants can calculate the social benefit of each project. This should render implementing the most efficient project more likely. We thus expect more equal underbidding and higher implementation rates of the most efficient projects in the public than in the private information setting (Hypothesis 1). Other-regarding concerns like inequity aversion and welfare enhancement may further promote the emergence of such a pattern. We also expect the size of costs and personal values to influence bidding behaviour and provision.

[Table 1 about here]

Table 1 provides a description of the 5 prospects implemented in our experiment. Prospect 1 is our baseline prospect and the values in prospects from 2 to 5 in Table 1 are obtained as variations of Prospect 1 . In Prospects 1 to 4 we keep the social benefit of the most efficient project (with respect to social benefit) constant (namely 54). The aim is to explore how the implementation of projects with the same potential welfare gain (expressed by the social benefit) is affected by different patterns of personal values and costs. In Prospects 2 to 4 we adjust both 
personal values and costs to test how different patterns of these affect bidding and implementation. Changing both personal values and costs allows us to explore a wider range of settings. Its drawback is that we cannot directly disentangle the effect of variations in costs and personal values by comparing the prospects, but only do so by using a multivariate regression analysis. In Prospect 5 we explore the effects on implementation of three projects with relatively high social benefit, one higher and the other lower than 54 .

In Prospect 2 we keep the social benefit of all the projects the same as in Prospect 1 by reducing the costs. Keeping the social benefit the same as in Prospect 1 requires an equivalent change in the sum of personal values. By this manipulation we want to explore the impact of a cost reduction while keeping the social benefit unchanged. Experimental evidence has shown that lower implementation thresholds in public goods games, while decreasing contributions, increase the probability that public goods are implemented (Ledyard, 1995). In our context, the cost of a project may be interpreted as an implementation threshold. If people focus more on costs than on social benefits, it may be, in analogy to what happens in threshold public goods games, that projects with lower costs generate lower bids, but still are more likely to be implemented (Hypothesis 2). Of course, we cannot draw any conclusion directly from a comparison of the Prospects since more than one dimension needs to be changed at the same time. For this purpose, one has to refer to the regression analysis.

In Prospect 3, all participants enjoy the same positive personal values but the social benefit of the projects is the same as in Prospects 1 and 2. Our main aim is to check for the impact of "equal personal values". Highly unbalanced personal values render predictions about others' behaviour more difficult and bidding behaviour more variable. When all participants are assigned the same personal value, it should be easier for them to predict other participants' behaviour and to coordinate on bids ensuring project implementation or even equilibrium bids. Relying on evidence collected in public goods games, we expect higher variance in personal 
values to negatively affect contributions and, as a consequence, to have a negative

effect on implementation. Thus, Prospect 3 should have the highest contribution

levels and implementation rates (Hypothesis 3). ${ }^{16}$

Prospect 4 comprises the largest number of negative personal values. Evidence about loss aversion and framing (e.g., Kahneman et al., 1991) suggests that negative personal values should have a stronger impact on bids and on the implementation than corresponding positive values. Particularly in the private information setting, negative personal values are expected to lead to higher underbidding (Hypothesis $4 \mathrm{a})$.

The seminal work of Schelling (1958) highlighted the importance of focal points for coordination and efficiency in strategic interactions. In this perspective, behaviour in Prospects 4 and 5 allows us to test whether the salience of the most efficient project affects its likelihood of being implemented. In Prospect 4, the difference between the social benefit of the most efficient project and the second most efficient project is much larger than in prospects 1,2 and 3 (45 versus 15$)$. We expect that the prominence of the most efficient project will improve coordination on this project (Hypothesis 4b). Further evidence about the importance of salience for the implementation of the most efficient project may come from Prospect 5. In this prospect, three projects $(A B, A C$ and $B C)$ generate relatively high social benefits, with project $B C$ being the most efficient (in terms of social benefit) and $A B$ being second most efficient, with a social benefit equal to the highest social benefit in the other prospects. This may endanger the implementation of the most efficient project because its salience is attenuated by the other efficient projects (Hypothesis 5).

Beyond the effects of costs, heterogeneity in values, negative values, and social benefit, however, the experiment should be understood as an exploratory study of a procedurally fair institution. The key objective is to learn about bidding behaviour

16 In experimental bargaining games, asymmetries in payoffs often lead to bargaining failures (Kagel et al., 1996; Schmitt, 2004). While in the bargaining literature this failure may be attributed to conflicting fairness norms, this is not the case in our game, where the only salient fair and efficient behaviour is bidding one's personal value, even if it is negative. 
in the institution and to verify whether applying the proposed mechanism provides the project that delivers the highest social benefit.

\subsection{Participants and Procedures}

The experiment was run in Jena (Germany) at the laboratory of the Max Planck Institute of Economics. Participants were recruited among students of the Friedrich Schiller University of Jena using the ORSEE system (Greiner, 2004). The computerised experiment was programmed and conducted using the z-Tree software (Fischbacher, 2007). A total of 57 participants took part in two experimental sessions in which the two information conditions were separately administered: 30 individuals participated in the public information condition and 27 in the private information condition.

Upon their arrival at the laboratory, participants were randomly allocated to cubicles inhibiting interaction with other participants. Each participant received written instructions and read them privately. After that, a member of staff read the instructions aloud and participants were given the opportunity to privately ask staff members for clarifications. The experiment started only after each participant had answered a control questionnaire checking their understanding of the instructions.

Each participant in the experiment was exposed to all prospects and to all personal values of Table 1 over 15 independent rounds. ${ }^{17}$ During the experiment participants received no feedback (about the project implemented or bids of others in the group). We thus did not study learning dynamics but only wanted to check whether more familiarity with the complex setup affects behaviour and outcomes. At the end of the experiment, one of the 15 rounds was randomly selected for payment and participants were informed about the project that was implemented and about their payoff for that project. Payoffs in the experiment were added

17 A series of Wilcoxon Rank Sum tests reveals that rounds based on the same prospect can be pooled together. 
to a $€ 5$ show-up fee and payments were privately dispensed in cash at the end of the experiment. The instructions reminded participants that earnings in the experiment could be negative. In case of negative earnings, the following procedure was used: first, the show-up fee was used to cover the losses; second, when losses exceeded the show-up fee, participants could pay the difference out of pocket money or take part in a boring task (i.e., computing the frequency of letter " $t$ " in a text), with the length of the task being proportional to losses not covered by the show-up fee.

\section{Results}

\subsection{Bids}

Figures 1 and 2 show the distribution of bids for each combination of prospects and projects in the private and public information condition, respectively. The boxplots in each cell provide the conventional representation of the distributions of bids for each personal value (identified by a filled circle).

[Figure 1 about here]

In Figure 1, the median is always below the personal value. This signals a tendency to underbid one's own personal value. This tendency seems to be stronger for higher (absolute) personal values.

[Figure 2 about here]

Comparing Figures 2 and 1, introducing common knowledge of personal values does not heavily affect bidding behaviour. The same pattern of choices emerging for the private information condition is observed also for the public information condition (Wilcoxon Rank Sum tests, all p-values $\geq 0.429) .{ }^{18}$ This provides evidence against Hypothesis 1.

18 To warrant independence of observations, the tests are performed employing average values at the individual level. 
3.2 Bids and Personal Values

Figure 3 focuses on relative deviations between bids and personal values. Specifically, a measure of relative deviation for each project $\left(R_{i}\right)$ is computed by taking the ratio of the difference between the bid for a given project $b_{i}$ and the personal value for that project $v_{i}$ and the absolute value of the personal value $\left(R_{i}=\frac{b_{i}-v_{i}}{\left|v_{i}\right|}\right)$. Figure 3 portrays the distribution of the individual-level average $R_{i}$, in the five distinct prospects of the private information and public information condition.

[Figure 3 about here]

Figure 3 confirms the prevalence of underbidding in participants' behaviour. The distributions of relative deviations are generally located under the threshold (dashed line) separating overbidding from underbidding, both in the public and private information conditions. When comparing the two information conditions, no major differences are observed. The average relative deviations in the two conditions are very similar (continuous line) and no significant differences are observed when comparing the two conditions prospect by prospect (Wilcoxon Rank Sum tests, all p-values $\geq 0.243)$.

A series of Wilcoxon Signed Rank tests highlights some significant differences in relative deviations across distinct prospects. In the private information condition, underbidding is stronger for Prospect 2 than for all other prospects (all p-values $<0.05)$. In the public information condition, stronger underbidding is observed for Prospect 2 than for all other prospects (all p-values $<0.05$ ), but Prospect 1 (p-value $=0.171)$. In line with Hypothesis 2, lower costs seem to deplete bids. As noted in 2.2 , the results are indicative more than conclusive with regard to our hypotheses, as more than one dimension has changed.

\subsection{Implemented Projects}

The tendency of participants to post bids that are lower than their personal values negatively affects the creation of surplus and endangers the implementation of 
projects. Figure 4 provides a comparison between the average surplus and the social benefit of each project in the two information conditions.

[Figure 4 about here]

Figure 4 shows how the strong underbidding observed in the experiment negatively affects the creation of a positive surplus, even for projects delivering positive social benefits. In terms of surplus creation, no major differences are observed between the public and private information conditions. To complement the analysis of surplus creation, Table 2 reports on the frequency of implementation of each project. The frequencies in the table are computed taking into account all possible combinations of bids collected for that project in each round, irrespectively of the group to which participants belonged. ${ }^{19}$

[Table 2 about here]

Table 2 shows that the project delivering the highest social benefit is the most frequently implemented project, both in the public and private information condition. The highest frequency of implementation for the socially most desirable projects is registered in Prospect 3, for both information conditions (evidence in support of Hypothesis 3). In contrast, the lowest frequency of implementation for these projects is registered in Prospect 2 and in Prospect 5 for the private and public information condition, respectively. The latter points in the direction of Hypothesis 5, while the implementation problems registered in Prospect 2 conflict with our Hypothesis 2. The highest rate of failure is registered in Prospect 4 for both information conditions, probably due to the high number of projects with negative value in this prospect (see Hypothesis $4 \mathrm{a}$ ).

When comparing the frequency of implementation of the most efficient project across information conditions, no significant differences emerge (Wilcoxon Rank

19 Given that participants did not receive any feedback during the experiment, groups do not affect choices over the course of the experiment. Consequently, a better measure of project implementation is obtained by taking into account all possible combinations of bids for a given project in a given round and not only the bids in each group of three participants. This implies that, in each round and for each project, $10^{3}$ and $9^{3}$ triplets of bids are obtained in the public and private information conditions, respectively. 
Sum tests, all p-values $>0.255) .{ }^{20}$ Similarly, no significant differences are observed when comparing failure frequencies for all projects across the two conditions (Wilcoxon Rank Sum tests, all p-values $>0.289$ ). These results provide strong evidence against Hypothesis 1.

The comparison of implementation frequencies of the most efficient project across prospects highlights some significant differences. In the public information condition, we register highly significant differences when comparing Prospect 2 to Prospects 3 and 4 (Wilcoxon Signed Rank test, p-values equal to 0.021 and 0.031 , respectively). These results support our Hypotheses 3 and $4 \mathrm{~b}$.

Weakly significant differences are registered when comparing Prospect 3 to Prospect 1 and Prospect 5 (Wilcoxon Signed Rank test, p-values equal to 0.065 and 0.051 , respectively). In the private information condition, we register a weakly significant difference when comparing Prospect 4 to Prospect 3 (Wilcoxon Signed Rank test, p-value equal to 0.072). These results support Hypotheses 3 and 5.

\subsection{Regression Analysis}

The descriptive analysis reported above underlines some patterns of behaviour with respect to bidding and project implementation. In this section, a regression analysis investigates the determinants of bidding behaviour, with particular attention paid to deviations from personal values. A better understanding of bidding behaviour provides us with insights about the source of surplus creation and project implementation.

Table 3 presents the results of a regression analysis based on a linear mixedeffects model with random effects to control for repeated observations at the individual level. The dependent variable in the model is the relative deviation of bids $\left(b_{i}\right)$ from personal values $\left(v_{i}\right)$ expressed in percentage terms. A positive sign

\footnotetext{
20 To warrant independence of observations, we computed the frequency of implementation of the socially most desirable projects at the group level for both information conditions. The difference in the central tendencies of the distributions thus computed was then tested with the support of a non parametric test. The same procedure was followed for the other tests reported in this section.
} 
for the dependent variable identifies overbidding, while a negative sign identifies underbidding. ${ }^{21}$ The dependent variable is regressed on the following explanatory variables: Personal.value is the personal value assigned to a subject for the project; Project.cost is the cost of the project; Personal.values.SD is the standard deviation of personal values for the project considered; Personal.value. $N E G$ is equal to 1 if the personal value is negative, and is equal to 0 otherwise; Soc.benefit is the social benefit and measures the efficiency of the project; Public.info is equal to 1 for the public information setting, and it is equal to 0 for the private information setting; Round, indicates in which of the 15 rounds choices were made. In addition to main effects, some interactions between explanatory factors are considered in the regression, with particular attention paid to the impact of public information. Finally, Prospect \# provides us with a control on the prospect in which bids were collected.

[Table 3 about here]

The regression output reported in Table 3 confirms the overall tendency to underbid, as can be seen from the negative and highly significant intercept coefficient. Furthermore, as shown by the coefficient of Personal.value.NEG, more aggressive underbidding is registered among those with negative personal values (in support of Hypothesis 4a). When personal values fall in the positive domain, an increase in personal values reduces relative underbidding (Personal.value). By contrast, higher negative personal values trigger stronger relative underbidding (Pers.valuexPers.val.NEG). Both higher costs for the project (Project.cost) and higher variance in personal values (Personal.values.SD) foster relative underbidding (evidence in support of Hypothesis 2 and Hypothesis 3, respectively).

Concerning the impact of information, common knowledge of others' values has a significant impact on bidding behaviour via awareness of the variance in personal values (Pers.val.SD $\times$ Public.info), but not via awareness of the social benefits gen-

21 The dependent variable $R e l . d e v_{i}=\frac{b_{i}-v_{i}}{\left|v_{i}\right|} \times 100$ cannot be computed for those having a personal value equal to zero. Accordingly, the regression analysis is conducted on 5757 observations out of the 5985 available. 
erated by the projects (Soc.benefit $\times$ Public.info) (evidence against Hypothesis 1).

When compared to the baseline condition provided by Prospect 1 , two prospects

\section{Discussion and Conclusions}

Based on three requirements for an ethically desirable mechanism to regulate public provision, we have derived a common game format. One could claim-using jargon of social psychology - that this game format is procedurally fair. As for procedurally fair sports contests, this could crowd-in material opportunism in the sense that the parties involved are mainly motivated by their own material, here monetary, incentives.

Although bidding personal values would seem an obvious simple heuristic that would lead to fair and efficient outcomes, this is hardly ever observed. Rather, nearly all participants understood the incentives for strategic underbidding and yielded to them.

Our experimental setting allows us to identify a few project characteristics affecting underbidding and, as a consequence, creation of surplus. In particular, underbidding seems to be weaker for positive than for negative personal values. Moreover, higher positive personal values induce less relative underbidding, while the opposite holds for negative values.

With respect to the impact of information, we observe common knowledge of others' values to induce more underbidding for a given level of dispersion in personal values. In terms of surplus creation, there are no striking differences when comparing the private and public information treatments: for both, the most efficient project is most frequently implemented, with rates comparable to those reported by Güth et al. (2011). Outcome-based social preferences should affect behaviour in the public information condition only. The overall consistency of 
behaviour and outcomes across information treatments suggests that in our complex and thereby more realistic setting, social preferences of this kind do not play a relevant role and are, possibly, crowded-out by the procedural fairness of the mechanism. However, further research is needed to understand how the two concepts of fairness interact and when they matter.

When assessing behaviour across prospects, a few patterns emerge. First, Prospect 3, characterised by homogeneous positive personal values, is the prospect most frequently resulting in the most efficient project. Second, in Prospect 5 there is a competing project which is similar in terms of social benefits to the most efficient project. This seems to negatively affect implementation of the most efficient project, in line with the hypothesis of a positive impact of saliency on implementation. Third, Prospect 2 provides a larger underbidding margin before endangering implementation of efficient projects. ${ }^{22}$ Accordingly, participants underbid more, on average, in this prospect than in others. For this prospect, the general tendency to underbid less, in relative terms, for lower project costs is countervailed by strategic considerations triggered by underbidding margin.

Altogether, heterogeneity in personal values and negative values seem to endanger implementation of efficient projects. Knowing the value of others does not seem to matter much as one mainly conditions on her own value when bidding. With heterogeneous personal values, projects with very high social benefits are less endangered by underbidding than projects with positive, but smaller, social benefits.

Some inefficiency due to the difficulties to coordinate underbidding had to be expected since the mechanism, as characterised by the three requirements, is not incentive-compatible. Nevertheless, large social benefits serve as a safeguard, allowing provision even in case of underbidding. Altogether, our experiment reveals some surprising practical functionality of the proposed mechanism which guaran-

22 As a measure of underbidding margin, we compute the relative underbid which, when jointly implemented, generates nil surplus. In Prospect 2, the average underbidding margin across projects is equal to 0.339 , while for other prospect the same measure is always smaller than 0.250 . 
552 tees citizen sovereignty in public provision, similar to what happens for private 553 goods, and generally warrants the implementation of the most efficient projects. 


\section{References}

Andreoni, J. (1995). Warm-glow versus cold-prickle: The effects of positive and negative framing on cooperation in experiments. Quarterly Journal of Economics, 110(1), 1-21.

Andreoni, J. and Miller, J. (2002). Giving according to GARP: an experimental test of the consistency of preferences for altruism. Econometrica, 70:737-753.

Bagnoli, M. and McKee, M. (1991). Voluntary contribution games: Efficient private provision of public goods. Economic Inquiry, 29(2), 351-366.

Bagnoli, M. and Lipman, B. (1989). Provision of public goods: Fully implementing the core through private contributions. Review of Economic Studies, 56, 583601.

Bergstrom, T., Blume, L., and Varian, H. (1986). On the private provision of public goods. Journal of Public Economics, 29(1),25-49.

Bolton, G. E. and Ockenfels, A. (2000). Erc: A theory of equity, reciprocity, and competition. The American Economic Review, 90(1):pp. 166-193.

Cadsby, C. and Maynes, E. (1999). Voluntary provision of threshold public goods with continuous contributions: experimental evidence. Journal of Public Economics, 71, 53-73.

Charness, G. and Rabin, M. (2002). Understanding social preferences with simple tests. The Quarterly Journal of Economics, 117(3):817-869.

Fehr, E. and Schmidt, K. M. (1999). A theory of fairness, competition and cooperation. The Quarterly Journal of Economics, 114(3):817-868.

Fischbacher, U. (2007). z-Tree: Zurich Toolbox for Ready-made Economic Experiments. Experimental Economics, 10(2), 171-178.

Frey, B. S. and Oberholzer-Gee, F. (1997). The cost of price incentives: An empirical analysis of motivation crowding-out. American Economic Review, 87(4), $746-755$.

Gigerenzer, G. and Todd, P. M. (2000). Simple heuristics that make us smart. Oxford University Press, USA. 
Greiner, B. (2004). An Online Recruitment System for Economic Experiments. In K. Kremer and V. Macho, editors, Forschung und wissenschaftliches Rechnen 2003. GWDG Bericht 63, Göttingen : Ges. für Wiss. Datenverarbeitung.

Güth, W. (1986). Auctions, public tenders, and fair division games: An axiomatic approach. Mathematical Social Sciences, 11(3), 282-294.

Güth, W. (2011). Rules (of bidding) to generate equal stated profits: An axiomatic approach. Journal of Institutional and Theoretical Economics, 167(4), 608-612.

Güth, W., Koukoumelis, A., and Levati, M. V. (2011). "One man's meat is another man's poison." An experimental study of voluntarily providing public projects that raise mixed feelings. Jena Economic Research Papers \# 2011-034.

Güth, W. and Kliemt, H. (2013). Consumer sovereignty goes collective: ethical basis, axiomatic characterization and experimental evidence. In M. Held, G. Kubon-Gilke, and R. Sturn, editors, Jahrbuch Normative und Institutionelle Grundfragen der Ökonomik. Band 12. Grenzen der Konsumentensouveränität. Metropolis.

Harsanyi, J. C. (1967). Games with incomplete information played by bayesian players. Management Science, 14(3):159-182.

Kagel, J. H. (1995). Auctions: A survey of experimental research. In J. H. Kagel and A. E. Roth, editors, The Handbook of Experimental Economics, chapter 7. Princeton University Press.

Kagel, J. H., Kim, C., and Moser, D. (1996). Fairness in ultimatum games with asymmetric information and asymmetric payoffs. Games and Economic Behavior, 13, 100-110.

Kahneman, D., Knetsch, J. L., and Thaler, R. H. (1991). Anomalies: The endowment effect, loss aversion, and status quo bias. The Journal of Economic Perspectives, 5(1), pp. 193-206.

Kunreuther, H. and Portney, P. (1991). Wheel of misfortune: A lottery/auction mechanism for siting of noxious facilities. Journal of Energy Engineering, $\mathbf{1 1 7}(3), 125-132$. 
Ledyard, J. O. (1995). Public goods: A survey of experimental research. In J. H. Kagel and A. E. Roth, editors, The Handbook of Experimental Economics, chapter 4. Princeton University Press.

Marks, M. and Croson, R. (1998). Alternative rebate rules in the provision of a threshold public good: An experimental investigation. Journal of Public Economics, 67, 195-220.

Rapoport, A. and Chammah, A. M. (1965). Prisoner's Dilemma. A study in conflict and cooperation. Ann Arbor, The university of Michigan Press.

Rondeau, D., Schulze, W. D., and Poe, G. L. (1999). Voluntary revelation of the demand for public goods using a provision point mechanism. Journal of Public Economics, 72(3), 455-470.

Schelling, T. C. (1958). The strategy of conflict prospectus for a reorientation of game theory. The Journal of Conflict Resolution, 2(3):203-264.

Schmitt, P. (2004). On perceptions of fairness: The role of valuations, outside options, and information in ultimatum bargaining games. Experimental Economics, 7, 49-73.

Sonnemans, J., Schram, A., and Offerman, T. (1998). Public good provision and public bad prevention: The effect of framing. Journal of Economic Behavior \&s Organization, 34(1), 143-161.

Tversky, A. and Kahneman, D. (1974). Judgment under uncertainty: Heuristics and biases. Science, 185, 1124-1130. 
5 Instructions (Translated)

Welcome to this experiment! You will receive $€ 5.00$ for showing-up on time.

We kindly ask you to read the instructions carefully. Communication with other participants is not permitted during the experiment. If you have doubts or if you want to ask a question, please raise your hand. An experimenter will come and answer your question. Please switch off your mobile phones. If you do not comply with these rules, we will have to exclude you from the experiment and you will not get any payment.

How much you are going to earn will depend upon your decisions and also upon decisions of other participants. Both your choices and choices of the others will remain anonymous and will never be associated to your name.

During the experiment, all monetary amounts are expressed in ECU (experimental currency units) and not in Euro. At the end of the experiment 1 ECU will be exchanged with 1 Euro.

In the experiment you are matched with two more participants whose identity will not be revealed. The three participants in a group are called Participant 1, Participant 2, and Participant 3. You will be told whether you are Participant 1, Participant 2 or Participant 3 in the upper right-hand corner of the screen.

The experiment extends over 15 rounds. At the end of the experiment, only one of the 15 rounds is randomly drawn to compute your actual earnings in the experiment.

The interaction in each round

In each of the 15 rounds, 7 projects with their corresponding costs and personal values are going to be displayed on your screen. The structure of the screen is the same in each round, but the costs and personal values associated with the different projects may vary in each round. Of the seven projects three are single projects and four are combinations of single projects. For each project you are given information about the cost associated with its implementation and about your personal evaluation of the project. The evaluation of the project is a positive number if you gain from its implementation and a negative number if you suffer a loss from its implementation. This number is called personal value $\left(V_{i}\right)$. [Public Information only] You are also informed about the personal values of the other two participants in your group. Based on the information you are given, you are requested to submit a bid $\left(b_{i}\right)$ for each project. Your bids and the bids of the two other participants in your group determine your payoff. Bids can be expressed only as integer values, either positive or negative (for example: .., $-1,0,1, \ldots$ ).

\section{Payoffs}

The surplus of each project is defined as the difference between the sum of the bids for that project by the three participants in a group $\left(b_{1}+b_{2}+b_{3}\right)$ and the cost of that project $(c)$. Thus, the surplus is given by the formula $S=\left(b_{1}+b_{2}+b_{3}\right)-c$. The project with the highest non-negative surplus is implemented. If the highest surplus is negative, no project is implemented and your payoff will be 0 ECU. 
When a project is implemented, the earnings of a participant are determined as follows:

- You receive your value $\left(V_{i}\right)$ for the chosen project plus one third of the surplus of the chosen project $(S / 3)$

- From this we subtract your bid for the chosen project

- Therefore you earn in total: $V_{i}+S / 3-b_{i}$

The following is an example of the kind of computer screen you will see during the experiment:

\begin{tabular}{|c|c|c|c|c|c|}
\hline Project & Cost & $\begin{array}{c}\text { Personal value } \\
\text { (participant 1) }\end{array}$ & $\begin{array}{c}\text { Personal value } \\
\text { (participant 2) }\end{array}$ & $\begin{array}{c}\text { Personal value } \\
\text { (participant 3) }\end{array}$ & My bid \\
\hline A & 15 & -12 & & \\
\hline B & 5 & 13 & & \\
\hline C & 7 & -9 & & \\
\hline A,B & 19 & 3 & & \\
\hline A,C & 23 & -18 & & \\
\hline B,C & 13 & 5 & & \\
\hline A,B,C & & & & & \\
\hline
\end{tabular}

In the Public Information condition the values of the other participants are displayed on the screen.

Suppose you are Participant 1 and consider your choice for project A. If the project were implemented, it would cost 15 ECU. You have a negative personal value for the project $(-12)$. If the project were implemented, you would suffer a damage of 12 ECU. You must bid for the project. The amount you bid is relevant for the implementation of the project and for the amount you will have to pay or you will receive if the project is implemented. Suppose that the overall surplus of this project amounts to $30 \mathrm{ECU}$ and that this is the highest surplus. This means that Project $\mathrm{A}$ is implemented. Each participant gets an equal share of the surplus thus, each member of the group receives 10 ECU. If you bid -14 ECU for the project, your payoff is calculated as follows: $-12+10-(-14)=12$. It is made up of the following elements: in your role as Participant 1, you will suffer a damage of $V_{1}=-12$ ECU from project A, your share of the surplus is $10 \mathrm{ECU}$ and you have bid -14 ECU. Since 1 ECU equals 1 Euro, you would earn 12 Euro.

As a second example, suppose that Project B had the highest surplus and is, thus, implemented. Assume, furthermore, that the overall surplus of the project 
is 6 ECU. If your bid was 13 ECU, your payoff will be $13+2-13=2$ ECU. You will have to bid for all seven projects in the column "My bid".

It can be the case that the payoff for one or more participants is negative. However, this can only occur if the participant submits a bid that is higher than his personal value, that is $b_{i}>V_{i}$ (for instance, when the personal value $V_{i}$ for the project is 17 and the bid bi is larger than 17 or when the personal value $V_{i}$ for the project is -10 and the bid $b_{i}$ is larger than -10 ). If you submit a bid equal to your personal value or lower, you cannot get a negative payoff. If you, nevertheless, get a negative payoff, this will be dealt with in the following way:

- first, the amount you lose will be deducted from the 5 Euro that you receive for showing-up on time

- if your negative payoff exceeds 5 Euro, there are two alternatives. The first is that you pay the difference out of your own pocket. The second is that you carry out an additional task before you leave the laboratory to make up for the remaining difference. This additional task consists of looking for a specified letter in a longer text and counting the number of times it occurs. You will get 1.00 Euro for each sentence that you process correctly. Please note that the task is for settlement of potential negative payoffs only. Under no circumstance is it possible to carry out the task to increase a positive payoff.

Final payment

At the end of the experiment, one of the 15 rounds is randomly drawn for payment. You are going to be informed about:

1. the project which was implemented in that round (if any);

2. the surplus of the project;

3. your own bid;

4. your personal value;

5. and your payoff.

This information will only be displayed for the round that was randomly drawn. You will not be given any information on the bids of the other members of your group or on whether any project was implemented in the other rounds.

The payoff in the randomly drawn round is converted in Euro (for example, 15 ECU are 15 Euro). Your earnings will be privately paid in in cash, so that no other participant will know the size of your pay-out. 


\section{Tables}

Table 1 Prospects

\begin{tabular}{|c|c|c|c|c|c|}
\hline Project & $C(S)$ & $v_{1}(S)$ & $v_{2}(S)$ & $v_{3}(S)$ & $S B(S)$ \\
\hline \multicolumn{6}{|c|}{ Prospect 1} \\
\hline $\mathrm{A}$ & 30.00 & 30.00 & -30.00 & 45.00 & 15.00 \\
\hline B & 60.00 & 0.00 & 24.00 & 45.00 & 9.00 \\
\hline $\mathrm{C}$ & 36.00 & 6.00 & 18.00 & 18.00 & 6.00 \\
\hline $\mathrm{AB}$ & 90.00 & 30.00 & -6.00 & 105.00 & 39.00 \\
\hline $\mathrm{AC}$ & 45.00 & 36.00 & -12.00 & 75.00 & 54.00 \\
\hline $\mathrm{BC}$ & 96.00 & 6.00 & 42.00 & 63.00 & 15.00 \\
\hline $\mathrm{ABC}$ & 135.00 & 36.00 & 12.00 & 75.00 & -12.00 \\
\hline \multicolumn{6}{|c|}{ Prospect 2} \\
\hline $\mathrm{A}$ & 15.00 & 27.00 & 18.00 & -15.00 & 15.00 \\
\hline B & 30.00 & 27.00 & 0.00 & 12.00 & 9.00 \\
\hline $\mathrm{C}$ & 18.00 & 9.00 & 6.00 & 9.00 & 6.00 \\
\hline $\mathrm{AB}$ & 45.00 & -6.00 & 30.00 & 60.00 & 39.00 \\
\hline $\mathrm{AC}$ & 24.00 & 60.00 & -12.00 & 30.00 & 54.00 \\
\hline $\mathrm{BC}$ & 48.00 & 33.00 & 3.00 & 27.00 & 15.00 \\
\hline $\mathrm{ABC}$ & 69.00 & 33.00 & 18.00 & 6.00 & -12.00 \\
\hline \multicolumn{6}{|c|}{ Prospect 3} \\
\hline $\mathrm{A}$ & 30.00 & 15.00 & 15.00 & 15.00 & 15.00 \\
\hline B & 63.00 & 24.00 & 24.00 & 24.00 & 9.00 \\
\hline $\mathrm{C}$ & 48.00 & 18.00 & 18.00 & 18.00 & 6.00 \\
\hline $\mathrm{AB}$ & 105.00 & 48.00 & 48.00 & 48.00 & 39.00 \\
\hline $\mathrm{AC}$ & 45.00 & 33.00 & 33.00 & 33.00 & 54.00 \\
\hline $\mathrm{BC}$ & 93.00 & 36.00 & 36.00 & 36.00 & 15.00 \\
\hline $\mathrm{ABC}$ & 138.00 & 42.00 & 42.00 & 42.00 & -12.00 \\
\hline \multicolumn{6}{|c|}{ Prospect 4} \\
\hline $\mathrm{A}$ & 30.00 & -24.00 & -30.00 & -6.00 & -90.00 \\
\hline B & 60.00 & 0.00 & 24.00 & 45.00 & 9.00 \\
\hline $\mathrm{C}$ & 36.00 & 6.00 & 18.00 & 18.00 & 6.00 \\
\hline $\mathrm{AB}$ & 90.00 & -24.00 & -6.00 & 36.00 & -84.00 \\
\hline $\mathrm{AC}$ & 45.00 & -18.00 & -12.00 & 12.00 & -63.00 \\
\hline $\mathrm{BC}$ & 96.00 & 18.00 & 60.00 & 72.00 & 54.00 \\
\hline $\mathrm{ABC}$ & 135.00 & -9.00 & 33.00 & 75.00 & -36.00 \\
\hline \multicolumn{6}{|c|}{ Prospect 5} \\
\hline $\mathrm{A}$ & 30.00 & 78.00 & -30.00 & -12.00 & 6.00 \\
\hline B & 60.00 & 0.00 & 24.00 & 45.00 & 9.00 \\
\hline $\mathrm{C}$ & 36.00 & -6.00 & 18.00 & 18.00 & -6.00 \\
\hline $\mathrm{AB}$ & 63.00 & 30.00 & -18.00 & 105.00 & 54.00 \\
\hline $\mathrm{AC}$ & 45.00 & 6.00 & -24.00 & 105.00 & 42.00 \\
\hline $\mathrm{BC}$ & 57.00 & 15.00 & 42.00 & 60.00 & 60.00 \\
\hline $\mathrm{ABC}$ & 141.00 & 72.00 & 12.00 & 51.00 & -6.00 \\
\hline
\end{tabular}

Notes: The table shows the five different prospects, each one including seven projects, from A to $\mathrm{ABC}$, among which one might be chosen for implementation. For each project, $\mathrm{C}(\mathrm{S})$ represents the cost associated to its implementation, while $v_{1}(\mathrm{~S}), v_{2}(\mathrm{~S})$, and $v_{3}(\mathrm{~S})$ are the personal values of participant 1,2 , and 3 for a given project, respectively. $\mathrm{SB}(\mathrm{S})$ is the social benefit, namely the sum of personal values of participants 1,2 , and 3 minus the cost. 
Table 2 Frequency of Project Implementation

\begin{tabular}{|c|c|c|c|c|c|c|c|c|c|c|}
\hline \multirow[b]{2}{*}{$\%$} & \multicolumn{2}{|c|}{ Prospect 1} & \multicolumn{2}{|c|}{ Prospect 2} & \multicolumn{2}{|c|}{ Prospect 3} & \multicolumn{2}{|c|}{ Prospect 4} & \multicolumn{2}{|c|}{ Prospect 5} \\
\hline & Publ & Priv & Publ & Priv & Publ & Priv & Publ & Priv & Publ & Priv \\
\hline None & 19.9 & 21.9 & 10.0 & 8.2 & 17.5 & 11.7 & 27.0 & 36.3 & 9.2 & 10.7 \\
\hline A & 1.8 & 2.2 & 4.3 & 3.5 & 1.7 & 0.1 & 0.0 & 0.0 & 2.4 & 2.0 \\
\hline B & 0.6 & 0.3 & 0.5 & 0.3 & 0.0 & 0.0 & 1.6 & 2.1 & 0.1 & 0.0 \\
\hline $\mathrm{C}$ & 0.0 & 0.1 & 1.2 & 0.0 & 0.0 & 0.0 & 2.1 & 0.1 & 0.0 & 0.0 \\
\hline $\mathrm{AB}$ & 12.5 & 9.6 & 23.4 & 28.6 & 1.5 & 0.3 & 0.0 & 0.0 & 29.3 & 18.8 \\
\hline $\mathrm{AC}$ & 62.7 & 65.9 & 59.4 & 59.3 & 79.2 & 87.8 & 0.0 & 0.0 & 2.7 & 4.9 \\
\hline $\mathrm{BC}$ & 2.5 & 0.0 & 1.2 & 0.1 & 0.0 & 0.0 & 69.3 & 61.5 & 56.3 & 63.5 \\
\hline $\mathrm{ABC}$ & 0.0 & 0.0 & 0.0 & 0.0 & 0.0 & 0.0 & 0.0 & 0.0 & 0.0 & 0.0 \\
\hline
\end{tabular}

Notes: The table reports the frequencies of implementation for each project in all five prospects.

The private and the public information treatments are kept separate in the table.

A bold font identifies the project with the highest social benefits for a given prospect. 
Table 3 Determinants of relative deviations (linear mixed-effects model)

\begin{tabular}{lc}
\hline \hline Rel.dev & Coef (Std. Err.) \\
\hline (Intercept) & $-55.379(7.695)^{* * *}$ \\
Personal.value & $0.743(0.056)^{* * *}$ \\
Project.cost & $-0.205(0.033)^{* * *}$ \\
Personal.values.SD & $-0.210(0.107)^{*}$ \\
Personal.value.NEG & $-15.297(5.417)^{* *}$ \\
Soc.benefit & $0.102(0.048)^{*}$ \\
Public.info & $6.819(9.282)$ \\
Round & $-0.154(0.239)$ \\
Pers.value $\times$ Pers.val.NEG & $-3.932(0.276)^{* * *}$ \\
Pers.val.SD $\times$ Public.info & $-0.300(0.103)^{* *}$ \\
Soc.benefit $\times$ Public.info & $-0.051(0.055)$ \\
Prospect 2 & $-9.477(3.398)^{* *}$ \\
Prospect 3 & $7.156(4.224)^{\circ}$ \\
Prospect 4 & $5.653(3.578)$ \\
Prospect 5 & $-0.562(3.303)$ \\
\hline Num. Obs. & $5757(\mathrm{Subj}=57)$ \\
Wald $\chi^{2}$ (p-value) & $<0.001$ \\
\hline \hline
\end{tabular}

Notes: The dependent variable is the relative deviation of bids from personal values expressed in percentage terms; Personal.value captures the personal value assigned to a subject for the project; Project.cost captures the cost of the project; Personal.values.SD is the standard deviation of personal values for the project considered; Personal.value.NEG is equal to 1 if the personal value is negative, and to 0 otherwise; Soc.benefit captures social benefits of the project; Public.info is equal to 1 for the public information setting, and to 0 for the private information setting; Round, indicates in which of the 15 rounds choices were made. Three interaction terms between explanatory factors are then added in the regression and Prospect \# denotes the prospect in which bids were collected.

Significance levels: $* * * 0.001 ; * * 0.01 ; * 0.05 ;{ }^{\circ} 0.1$ 
Fig. 1 Bids (Private Information)

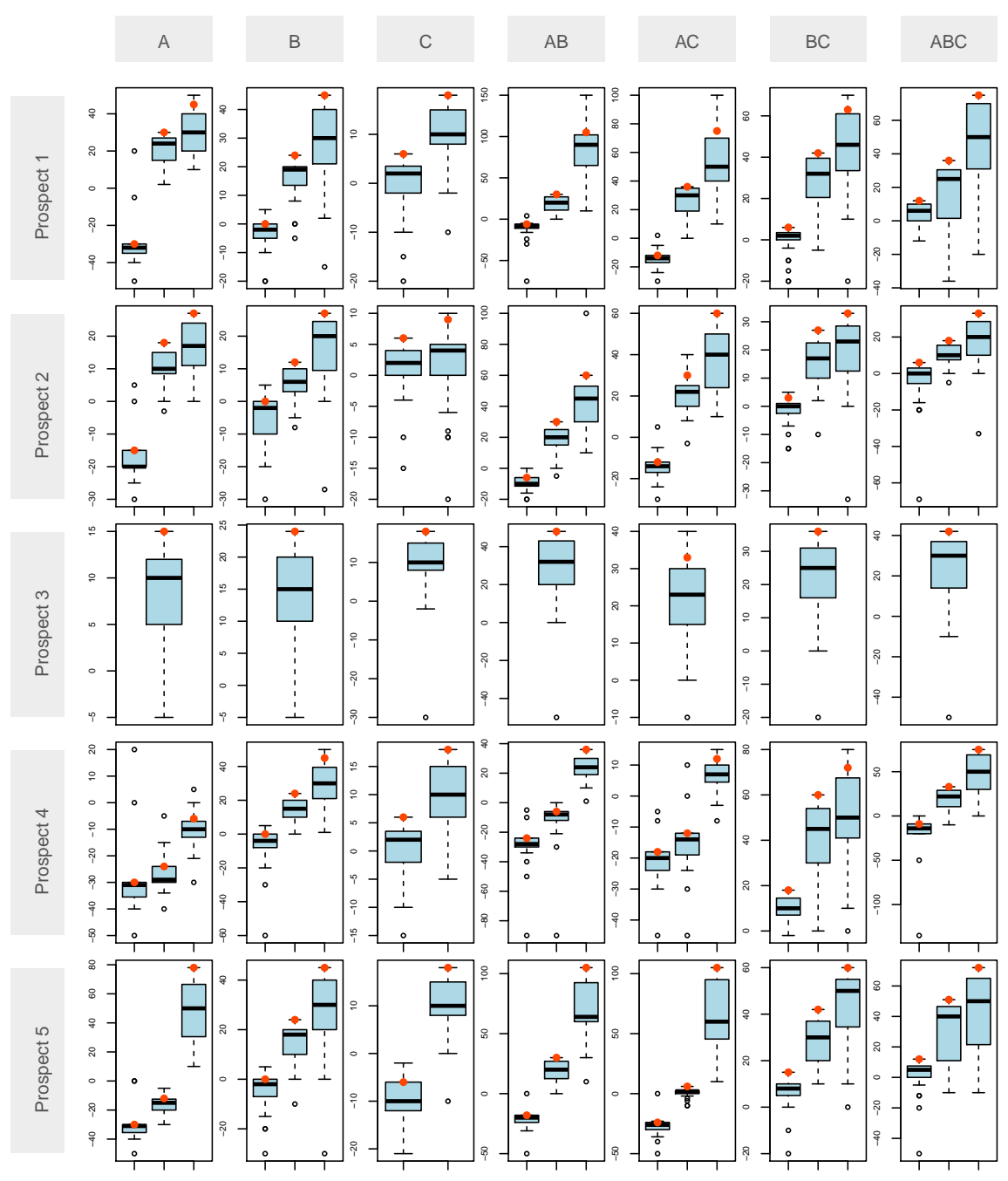

Notes: The figure reports the boxplots of the distributions of bids. Each cell corresponds to a project (from A to $\mathrm{ABC}$ ) of a specific prospect (from 1 to 5). The three boxplots portray the distributions of bids for each individual personal value, with the first plot from left referring to $v_{1}(\mathrm{~S})$ and the last plot from left to $v_{3}(\mathrm{~S})$. The filled circle in each boxplot represent the personal value. Values refer to the private information treatment. 
Fig. 2 Bids (Public Information)

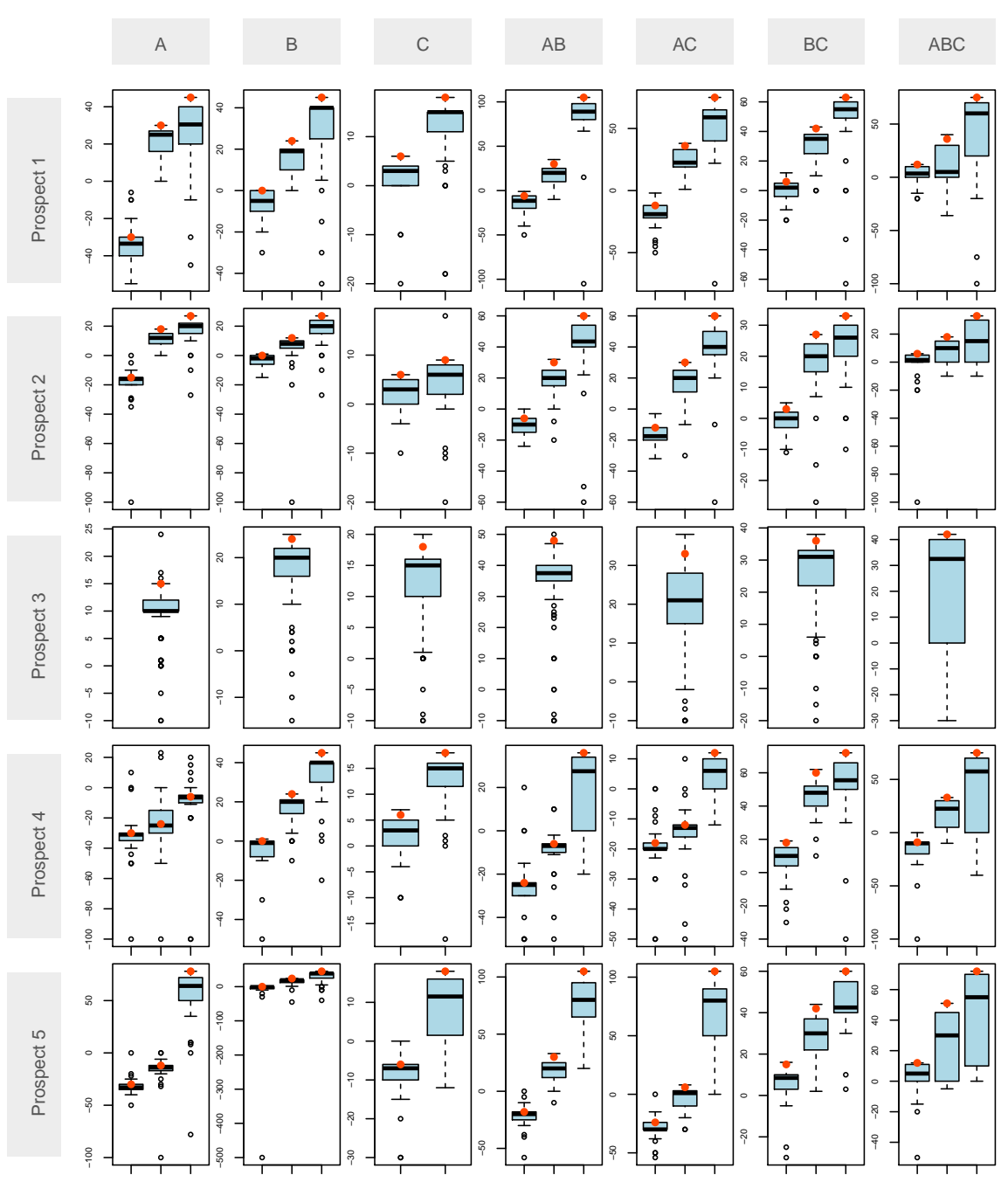

Notes: The figure reports the boxplots of the distributions of bids. Each cell corresponds to a project (from A to $\mathrm{ABC}$ ) of a specific prospect (from 1 to 5 ). The three boxplots portray the distributions of bids for each individual personal value, with the first plot from left referring to $v_{1}(\mathrm{~S})$ and the last plot from left to $v_{3}(\mathrm{~S})$. The filled circle in each boxplot represent the personal value. The values refer to the public information treatment. 
Fig. 3 Relative Deviations

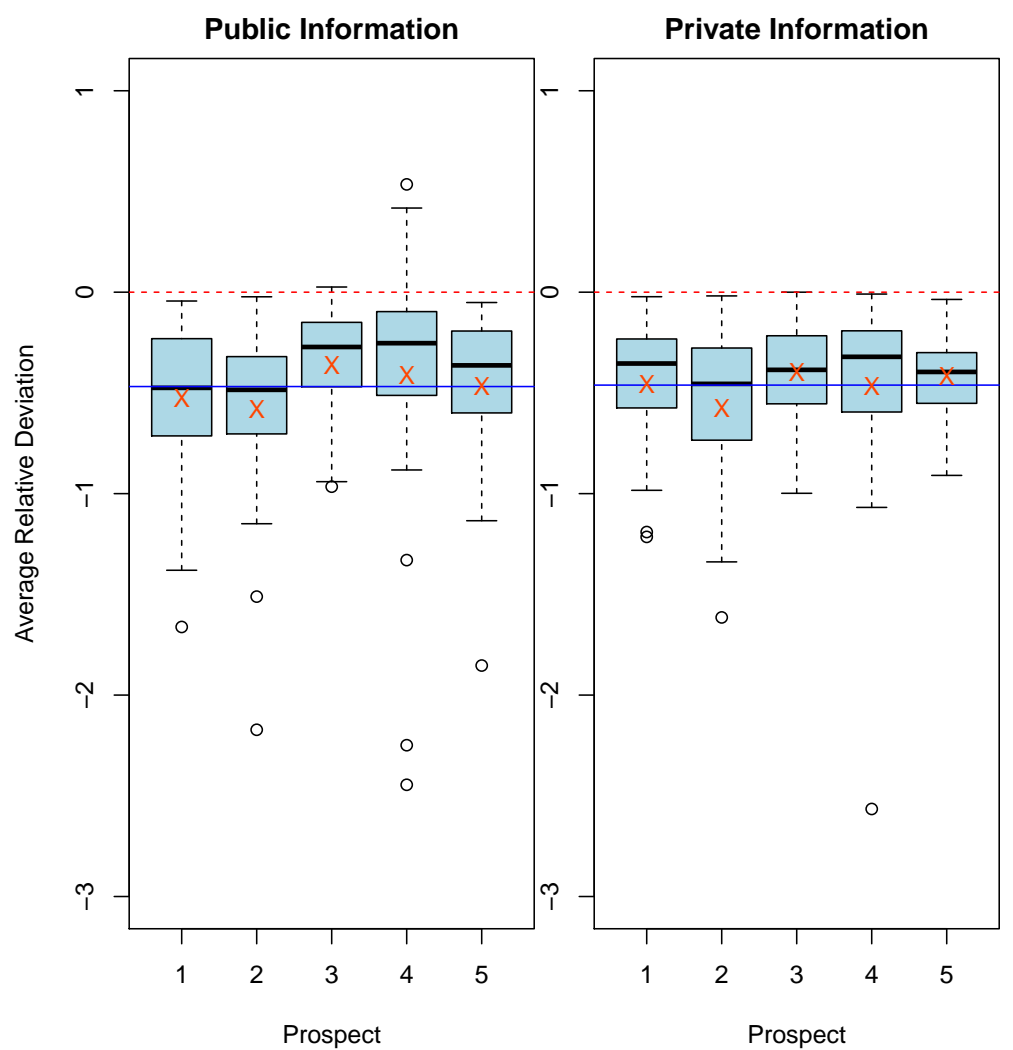

Notes: The figure shows the distribution of the individual-level average relative deviation of the bid from the personal value: $R_{i}=\frac{b_{i}-v_{i}}{\left|v_{i}\right|}$. The dashed horizontal line separates the overbidding area (above the line) from the underbidding area (below the line). 
Fig. 4 Surplus
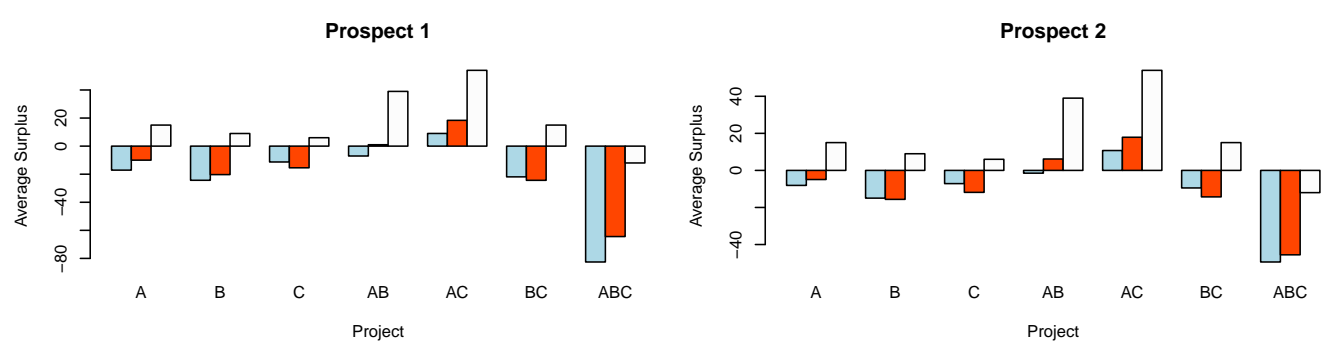

Prospect 3
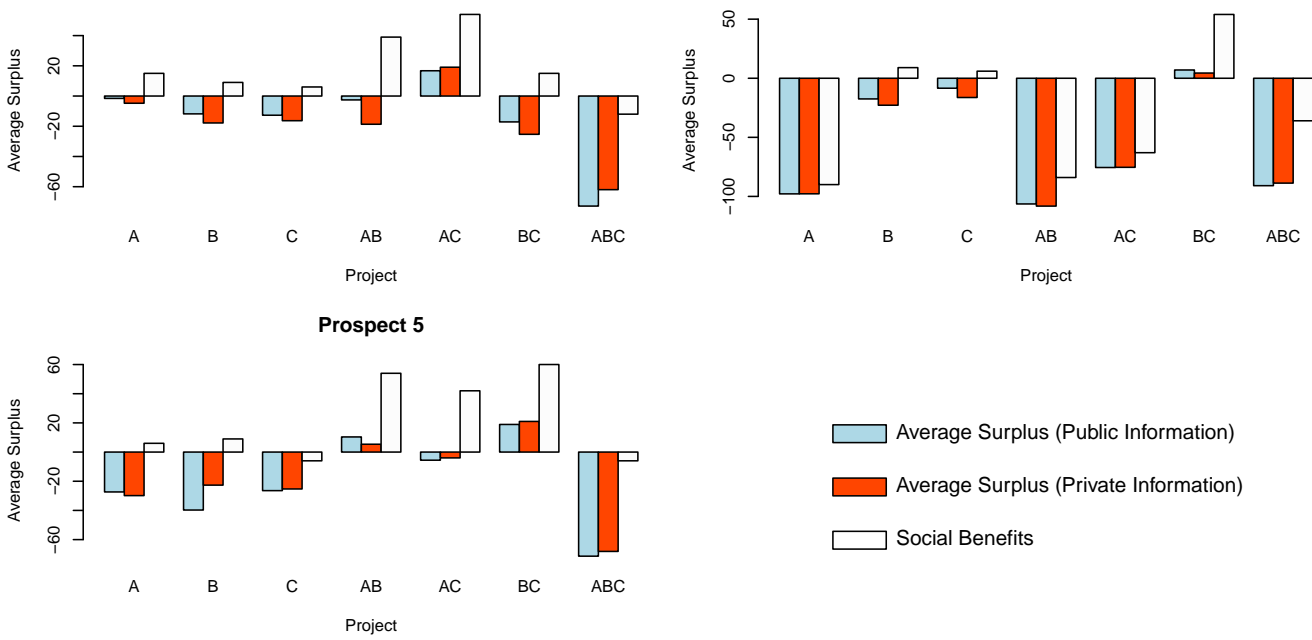

Notes: The figure reports the surplus (sum of the bids minus the cost for the project) and the social benefit (sum of the personal values minus the cost) for all projects within a prospect. 